\title{
Porosity and Micro-Hardness of Shrouded Plasma Sprayed Titanium Coatings
}

\author{
Hong Zhou \\ Centre for Engineering and Industrial Design, Waikato Institute of Technology, \\ Hamilton, 3240, New Zealand \\ zhouhong.nz@gmail.com
}

Keywords: Shroud; Plasma spray; Titanium coatings; Porosity; Micro-hardness.

\begin{abstract}
Titanium and its alloys are often used as key materials for corrosion protection. A promising approach to optimize both mechanical properties and corrosion resistance is the use of coating technologies. In this paper, shrouded plasma spray was used as a useful technology to produce low oxide containing titanium coatings. A solid shroud was used to plasma spray titanium coatings to reduce the oxide content. The titanium coatings were assessed by optical microscope, scanning electron microscopy and Vickers microhardness testing. The results showed that the shrouded titanium coatings exhibited an enhanced microstructure. The presence of the shroud and shroud gas flow led to a significant reduction in coating porosity because the reduction in air entrainment with the shroud resulted in better heating of the particles. The shrouded titanium coatings had a lower value of Vickers microhardness and a relative lower standard deviation than the air plasma sprayed titanium coatings.
\end{abstract}

\section{Introduction}

Titanium and its alloys play important roles in industries as light metals. The applications of titanium are mainly focused on its high specific strength at elevated temperatures, and unique corrosion resistance. This fact has predetermined the wide use of its alloys in space industries, and marine engineering as well [1-4]. Nowadays, titanium and its alloys are often used as key materials for corrosion protection because of the spontaneous and instant formation of a very chemically stable, highly adherent, and continuous protective oxide film on the surface. [5-6].

As we know, corrosion attack is mainly limited to the outer region of a component, and very often only localized areas may need protection. A promising approach to optimize both mechanical properties and corrosion resistance is the use of surface modification technologies, particularly coating technologies. Therefore, the protective coatings of titanium combined with cheap bulk materials offering the strength and ductility are supposed to provide sufficient protection and lower the cost [4].

Plasma spraying is considered as the most flexible coating technique due to a wide range of coating materials to meet many different needs [7-8]. However, air plasma spraying of titanium coatings is much difficult because titanium is a very reactive metal at high temperatures due to its strong affinity with gases such as oxygen, nitrogen and hydrogen, which lead to a degradation in the coating properties. Shrouded plasma spray can be considered as a useful technology to potentially produce low oxide containing titanium coatings. The attachment itself shields the plasma jet as it exits the torch. A gas shroud envelops the plasma jet as it leaves the attachment [9-15].

In this paper, Shrouded plasma spraying technology is used to deposit titanium coating on mild steel substrate. Air plasma sprayed titanium coatings were also deposited under the same spraying parameters. The difference between the two types of coating has been investigated in terms of porosity, microhardness, and microstructure. 


\section{Experimental Procedure}

Commercially available pure titanium powder (Xi'an Lilin International Trade Co., Ltd., Xi'an, China), with particle size range from $45 \mu \mathrm{m}$ to $75 \mu \mathrm{m}$ was used as feedstock powder for coating fabrication. The titanium powder was made by hydride-dehydride (HDH) method. The chemical composition of the HDH Ti powder is shown in table 1.

Table 1. Chemical composition of HDH titanium powder

\begin{tabular}{ccccccc}
\hline Element & $\mathrm{H}$ & $\mathrm{O}$ & $\mathrm{N}$ & $\mathrm{C}$ & $\mathrm{Fe}$ & $\mathrm{Ti}$ \\
\hline HDH Ti powder [wt\%] & 0.23 & 0.35 & $<0.03$ & 0.07 & $<0.11$ & Bal \\
\hline
\end{tabular}

A new design of shroud attachment was proposed for the plasma spraying of titanium coatings [9]. The titanium powder was then plasma sprayed by using a SG-100 plasma gun (Praxair surface technologies, USA) with the shroud attachment. The plasma gun used a high-speed Mach II anode hardware with a forward injection internal powder injector and was mounted on a 6-axis robot which sprayed the samples in a raster pattern. The spraying parameters are presented in table 2.

Table 2. The spraying parameters for the titanium coatings with and without the shroud

\begin{tabular}{ll|ll}
\hline Spray parameter & setting & Spray parameter & setting \\
\hline Current, [A] & 800 & Powder feed rate, [g/min] & 30 \\
Voltage, [V] & 80 & Spray passes & 10 \\
Primary gas, Argon, [slpm] & 85 & Spray distance, $[\mathrm{mm}]$ & 100 \\
Auxiliary gas, Helium, [slpm] & 18 & Transverse speed, [mm/s] & 500 \\
\hline
\end{tabular}

Special attention was given to adjusting the powder carrier gas flow rate within the shroud to generate an inflight particle trajectory with a low angle of deviation from the central axis to prevent build-up of powder on the inside wall of the shroud. Mild steel plates $(100 \times 25 \times 3 \mathrm{~mm})$ were used as the substrates which were degreased, and sand blasted before depositing titanium coatings onto them. The parameters for spraying with and without the shroud attachment were the same as indicated in table 2, except that there was a shroud gas flow in the shrouded plasma spray process. The trial for spraying with the shroud used argon as an external shrouding gas at the exit with a flow rate of $300 \mathrm{slpm}$. After each argon shroud gas trial, the interior of the shroud was cleaned to leave a dust free surface prior to the next trial.

Cross sectional samples were metallographically prepared for microstructural analysis. Scanning electron microscope (SEM, Hitachi S4700, Janpan) with second electron imaging was operated at $20 \mathrm{kV}$ to observe the microstructures and morphology of specimens. An Olympus BX60 optical microscope equipped with a digital camera was used to capture images for the porosity analysis of the titanium coatings. Porosity was then examined by using IQ image analysis software.

Microhardness test was performed by using a Vickers indentor (LECO, Mechigan, USA) with a load of $300 \mathrm{~g}$ for 15 seconds on the coatings cross sections. The cross sections of the titanium coatings were polished before indentations, and the distance between two indentations was at least three times the diagonal to prevent stress-field effects from nearby indentations. The Vickers microhardness was averaged from 10 indents per sample.

\section{Results and Discussion}

Titanium powder. Figure 1 shows the particle morphology of the HDH titanium powders. From the SEM image, it is clear to see that the HDH titanium powder presents an irregular shape, even some particles with sharp ends. As we know, the hydride-dehydride process is to resize large titanium pieces down to a finer particle size distribution through crushing, milling and screening. Thus, those processes result in the irregular particle shape of HDH titanium powders. The size of the particles in figure 1a is approximately $50 \mu \mathrm{m}$, also some small size titanium dust can be found on the outer surface of the big particles, as shown in figure $1 \mathrm{~b}$. Powder feedstock morphologies and size play an important role on the microstructure and properties of thermal sprayed coatings. Usually coarse powders produce a coarser and more open structured coating with less oxidation than fine powders, which is mainly due to the difference in surface area of the powder particles [8]. 


\section{Titanium coating analysis}

a)

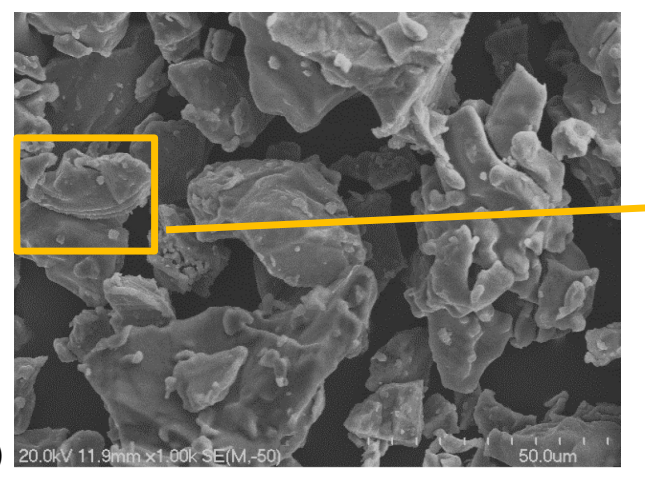

b)

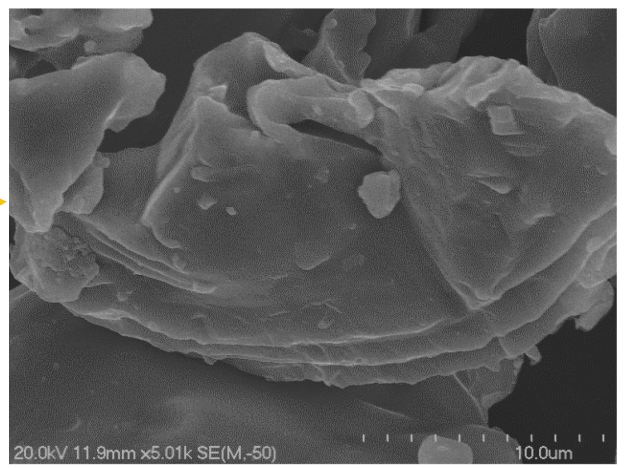

Fig. 1. SEM images showing the particle morphology of the HDH titanium powders. a) The HDH titanium powders with irregular shape; b) magnified region within the rectangle in a).

Microstructure and coating porosity. Figure 2 presents the second electron images (SEM) of polished cross sections of the titanium coatings with/ without the shroud at a similar low magnification. The SEM images reveal that the shrouded titanium coating has a dense microstructure with a low porosity; whereas the air plasma sprayed titanium coating possesses a high porosity. The SEM images demonstrate that the presence of the shroud results in a significant reduction in coating porosity. In principle the reduction in air entrainment with the shroud was expected to generate a better heating of the particles during plasma spraying. Therefore, more fully molten titanium particles at higher temperatures during in-flight were obtained, which helped decrease the porosity in the titanium coatings.

Images of the polished cross-sections of titanium coatings were captured by a digital camera attached to an optical microscope. Porosity distributions were then determined by using the IQ image analysis software. Special attention was required during metallographic preparation to prevent pull-out of internal titanium oxides and splats. Figure 3 presents the porosity results in the titanium coatings. The porosities of the titanium coatings with and without the shroud are $2.42 \pm 0.31$ and 3.53 \pm 0.45 , respectively, which shows that the presence of the shroud and shroud gas flow lead to a significant reduction in coating porosity.

Shrouded plasma spray is to modify plasma spray torches by using a gas-shrouded attachment onto an atmospheric plasma spraying torch. The attachment itself shields the plasma jet as it exits the torch. A gas shroud envelops the plasma jet as it leaves the attachment. The additional shroud gas, usually an inert gas such as argon, is injected around and envelopes the plasma jet, shielding the molten particles from coming in contact with oxygen from the surrounding environment, reducing the amount of entrainment of cold and heavy ambient air, and delaying the corresponding drop in velocity and temperature. Consequently, this retards particle cooling and reduces oxygen content and porosity of the resultant coatings. Meanwhile, gas-shrouded nozzles can extend the hot core of the jet by rearranging the gas flow to increase the dwell time of particles in the plasma [15]. Thus, better particle heating during the in-flight period was expected. The greater extent of particle heating with the shroud led to a better melting in the plasma and splat spreading on the substrate, which contributed to a reduction in porosity.

a)

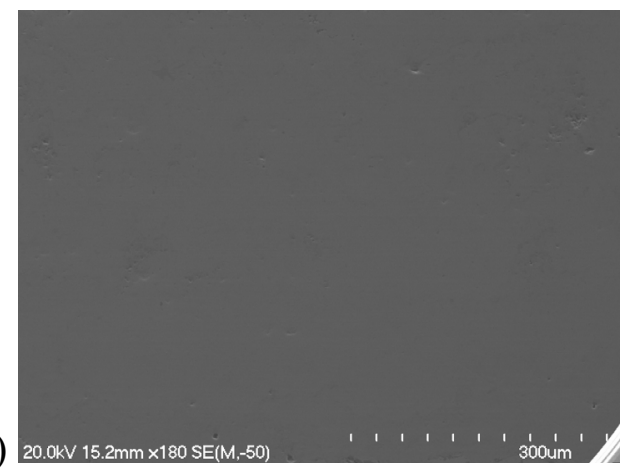

b)

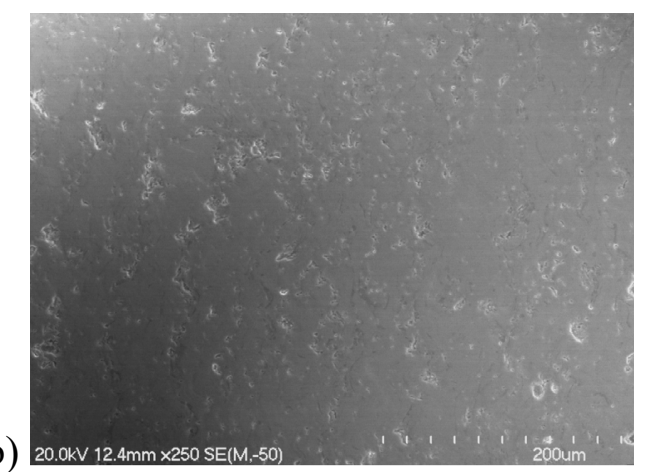

Fig. 2. SEM images showing the polished cross sections for a) plasma sprayed Ti coating with the shroud and (b) air plasma sprayed Ti coating without the shroud. 


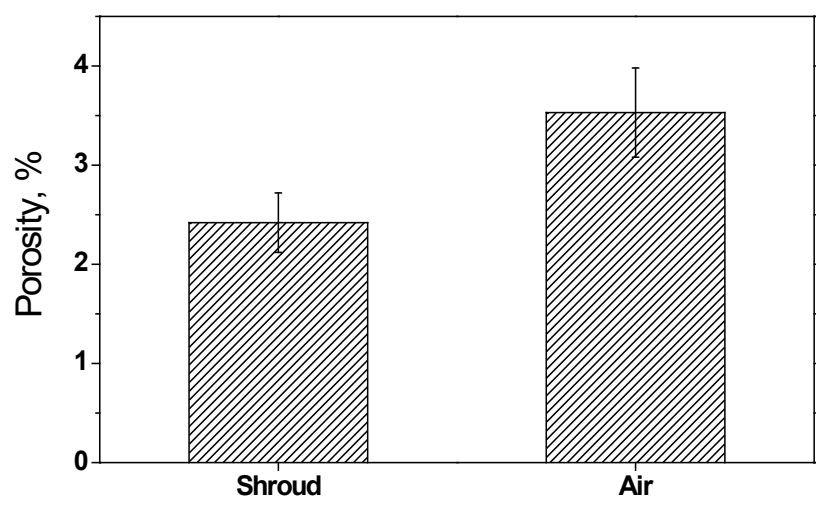

Plasma Sprayed Titanium coatings

Fig. 3. The porosity of the as-sprayed titanium coatings deposited with and without the shroud. The error bars represent the standard deviation.

Vickers Microhardness. The Vickers microhardness was examined for the as-sprayed titanium coatings with and without the shroud. In general, plasma sprayed coatings present high microhardness values due to the rapid cooling, oxidation, lamellar structure and residual stresses induced by the plasma spraying process. The mean microhardness values, as plotted in figure 4 , are $631.3 \pm 135.7 \mathrm{HV}$ for the air plasma sprayed titanium coating, and $404.2 \pm 103.2 \mathrm{HV}$ for the shrouded titanium coating, respectively. The air plasma sprayed titanium coating had a much higher Vickers microhardness than the shrouded titanium coating. The difference in percentage is up to $56 \%$ between the shrouded titanium coating and the air plasma sprayed counterpart. The reason for that should be mainly due to the oxygen/nitrogen content in the as-sprayed titanium coatings. The oxygen/nitrogen content in titanium has a significant effect on its mechanical properties because of embrittlement. Oxygen atoms ingress into the $\alpha$ phase titanium, and are interstitially incorporated into the lattice, either randomly or ordered at alternating (0002) planes of the hexagonal titanium lattice. Due to oxygen incorporation, the titanium ions are shifted towards the c-axis. Nitrogen dissolved into the $\alpha$ titanium can also change the lattice parameter. Incorporation of oxygen and/or nitrogen leads to anisotropic lattice distortion, thus hindering dislocation mobility and alters the sliding behaviour. Consequently, the microhardness would be high in the titanium with high oxygen/nitrogen content. Further, the formation of titanium oxides in the titanium coatings could also result in a significant increase of microhardness.

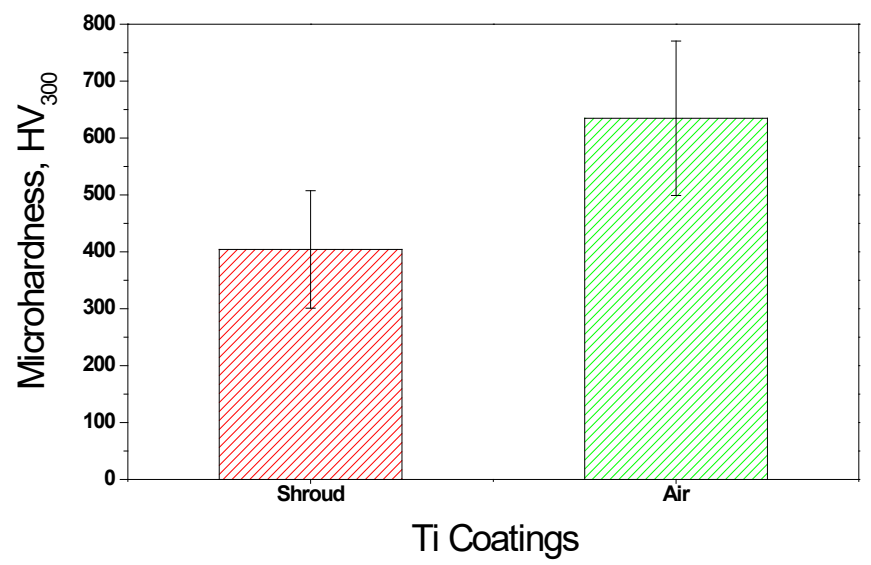

Fig. 4.Vickers microhardness of titanium coatings deposited with and without the shroud. The error bars represent the standard deviation.

The mean microhardness values in both types of titanium coating showed large standard deviations. A low standard deviation usually means a good uniform distribution. In this experiment, the large standard deviations verified a broad distribution of microhardness value for both types of titanium coating. The factors of influence on the microhardness of titanium coating include the oxygen content, formation of titanium oxide, splat adhesion, and process-related defects in the coatings such as porosity, void, microcracks, grain size, and residual stress effect so on. The 
microhardness distribution of plasma sprayed coatings can be highly skewed or broadly distributed due to those influential factors. When compared with the shrouded titanium coating, the air plasma sprayed titanium coating presented a relative larger standard deviation, which means a more skewed distribution. This reveals that the shrouded titanium coating has a relatively more homogeneous microstructure, less oxide content, less defects like void and microcracks, and lower porosity than the counterpart, which has also been discussed in the microstructural analysis.

\section{Conclusion}

This work presents the feasibility of using the shrouded plasma spraying to fabricate titanium coatings, and air plasma sprayed titanium coatings were also deposited under the same conditions. The presence of the shroud and shroud gas flow led to a significant reduction in coating porosity. The shrouded titanium coating had a dense microstructure with a very low porosity; whereas the air plasma sprayed titanium coating possessed a high porosity. The air plasma sprayed titanium coating had a much higher Vickers microhardness and a relative larger standard deviation than the shrouded titanium coating.

\section{References}

[1] C. Leyens and M. Peters: Titanium and titanium alloys (Wiley-VCH GmbH, 2003).

[2] R. Boyer: Mater. Sci. Eng., Vol. A213 (1996), p. 103.

[3] R. Boyer, G. Welsch, E. Collings: Materials properties handbook (ASM international,1994).

[4] H. Zhou, B. Gabbitas, S. Mathews: Proceedings of the 12th World Conference on Titanium, Vol.3 (2011), p 1287.

[5] K Luthra: Oxidation of Metals, Vol. 36 (1991), p. 475.

[6] S. Taniguchi, T. Shibata and S. Itoh: Materials transaction, Vol. 32 (1991), p. 151.

[7] P. Fauchais, M. Vardelle, S. Goutier: J. Thermal Spray Technology, Vol. 25 (2016), p. 1534.

[8] P. Fauchais, G. Montavon, G. Bertrand: J. Thermal Spray Technology, Vol. 19(2010), p. 56.

[9] H. Zhou, Z. Liu, L.Luo: MATEC Web of Conferences, Vol. 142(03006) (2018), p. 1.

[10] M. F. Morks, C.C. Berndt: Applied Surf. Sci., Vol. 256 (2010), p. 4322.

[11] S. Kim, S. Choi, G. H. Kim, S. H. Hong: Thin solid film, Vol. 518 (2010), p. 6369.

[12] M.P. Planche, H. Liao, C. Coddet: Surf. Coat Technol., Vol. 202 (2007), p. 69.

[13] I. Thomson, V. Pershin, J. Mostaghimi, S. Chandra: Plasma Chemistry and Plasma Processing, Vol. 21 (2001), p. 65.

[14] S Matthews: Surface and coating technology, Vol. 249 (2014), p. 56.

[15] M. Jankovic, J. Mostaghimi, V. Pershin: J. Thermal Spray Technol., Vol. 9 (2000), p. 114. 